\title{
A Transparência como Espetáculo: uma análise dos portais de transparência de estados brasileiros
}

\section{Transparency as Spectacle: an analysis of brazilian states \\ transparency websites}

Paulo Ricardo Zilio Abdala

Doutorado em Administração, Professor Adjunto da Universidade Federal do Rio Grande do Sul, Brasil, paulo.abdala@ufrgs.br.

http://lattes.cnpq.br/6838723975612043

Carlos Marcos Souza de Oliveira e Torres

Serviço Federal de Processamento de Dados, Brasil,

carlos-marcos.torres@serpro.gov.br,

RESUMO: O objetivo deste trabalho é avaliar a funcionalidade dos portais de transparência dos estados como fonte de acesso à informação e espaços de fortalecimento da participação e do controle social. Para isso, apresenta uma análise detalhada dos sites de transparência de cinco estados, um por região, adotando duplo procedimento: aplicação de um instrumento de avaliação de portais (Sales, 2012) e realização de uma busca ativa pelos repasses aos estados de um fundo de origem federal. Os resultados apontam as lacunas específicas de cada portal, destacando a dificuldade de acesso à informação e a baixa oferta de funções interativas, essenciais para o exercício do controle e da participação social. Conclui-se que os portais de transparência dos estados continuam sendo espaços que se limitam ao cumprimento da legislação, sem o desenvolvimento de funcionalidades que poderiam fomentar a cultura da política participativa, ainda restrita, em sua dimensão eletrônica, a um processo de espetacularização.

Palavras-chave: Portais de Transparência. Controle Social. Participação Social.

ABSTRACT: The objective of this study is to evaluate the functionality of Transparency Websites in Brazilian states as a source of access to information and as spaces for strengthening social participation and control. With this purpose, it presents a detailed analysis of Transparency Websites from five states, one pe region, adopting a dual procedure: application of a portal assessment tool (Sales, 2012) and conduction of an active search for transfers of public fund from federa to state government. The results show the specific shortcomings of each portal, highlighting the difficulty of access to information and the low supply of interactive functions, both essential to the performance of control and of social participation. It is concluded that the Transparency Websites remain being spaces limited to fulfill law demands, without developing features that could foster the participatory policy culture, still restricted, in its electronic dimension, to a spectacularisation process.

Keywords: Transparency Websites, Social Control, Social Participation

Texto completo em português: http://www.apgs.ufv.br Full text in Portuguese: http://www.apgs.ufv.br

\section{INTRODUÇÃO}

A popularização da internet no seu formato Web, no início da década de 1990, trouxe consigo a expectativa de uma renovação na participação da sociedade civil na esfera da decisão política, a partir de uma possível aproximação entre os cidadãos e os gestores públicos por meio dos espaços de participação eletrônica (Gomes, 2005).

O uso de tecnologias da informação e comunicação (TIC) nos governos encontra diferentes aplicações, divididas por Cunha e Miranda (2013) em administração pública, serviços públicos e democracia. Em termos de administração pública, discute-se o suporte das TIC para o planejamento, execução e avaliação de políticas públicas dentro da própria estrutura do aparelho de Estado. Já os serviços públicos mediados pelas TIC, incluem diversas formas de acesso a serviços por parte da população, como agendamento de consultas, solicitações diversas, reclamações, informações, etc., por meio de portais. Por fim, a participação social intermediada pela internet é outro tema importante, envolvendo a interação entre governos e cidadãos em diversos espaços, supostamente permitindo que as pessoas participem do processo de elaboração, controle e avaliação de políticas públicas, prática conhecida por controle social. Para isso, é preciso que os governos disponibilizem à população informações qualificadas e em tempo real, sendo a transparência um princípio fundamental para que este tipo de governança seja possível (Filgueiras, 2011).

Esta discussão, de maneira ampla, encontra-se inserida no contexto daquilo que vem sendo chamado de governo eletrônico, abarcando as formas de mediação eletrônica e institucionalizada entre governos e sociedade civil. Entretanto, em termos teóricos, o debate se multiplica em perspectivas contraditórias, algumas críticas, enviesadas pela dimensão política e pelas relações assimétricas de poder (Anjos \& Ezequiel, 2011; Filgueiras, 2011), outras valorizando a dimensão técnica (Akutsu \& Pinho, 2003; Borges, Nascimento \& Silva, 2005; Cruz et al., 2012; Juzzo, 2004; Lemos et al., 2004; Sales, 2012; Silva, 2005). Seja qual for a posição adotada, o ponto comum entre essas abordagens é o entendimento de que a inserção massiva das tecnologias da informação e comunicação (TIC) na vida contemporânea tem um impacto significativo sobre a administração pública.

Em decorrência dessas transformações, proliferam-se estudos sobre como os governos se preparam para prover informações, prestar serviços e aproximar o cidadão da esfera de decisão política por meio de ferramentas online, como sistemas, aplicativos e portais web. Tais iniciativas surgem como resposta à pressão social para o acompanhamento, avaliação e participação nos interesses públicos, mas também como ajuste a novas demandas da

Correspondência/Correspondence: Paulo Ricardo Zilio Abdala Universidade Federal do Rio Grande do Sul R. Sarmento Leite, 521, Porto Alegre - RS, 90050-

170, Brasil.

paulo.abdala@ufrgs.br 
legislação. Entre essas pesquisas, um dos temas mais recorrentes é a análise da transparência pública, avaliando o potencial e os limites do uso da internet como forma de potencializar o acesso à informação a partir do estudo de diferentes casos, privilegiando a dimensão técnica (Akutsu \& Pinho, 2003; Borges, Nascimento \& Silva, 2005; Cruz et al., 2012; Juzzo, 2004; Lemos et al., 2004; Sales, 2012; Silva, 2005).

Por outro lado, para além da discussão sobre a eficiência das ferramentas, há uma desconfiança com relação à própria possibilidade de haver transparência na gestão pública. Filgueiras (2011) desenvolve, baseado na teoria da agência, o argumento de que o processo de ampliação da transparência tem como objetivo a redução do déficit informacional entre aquele que delega o poder, o cidadão/eleitor, e os agentes empossados no aparelho de Estado, permitindo que os primeiros controlem melhor o resultado de suas escolhas. O problema, segundo o autor, é que mais informação não necessariamente significa melhor gestão pública ou mais cidadania. O que se observa na prática é a busca por uma moralização da política a partir da prestação de contas após o fato, não formando um horizonte normativo no qual as decisões seriam de conhecimento e domínio público. Já Anjos e Ezequiel (2011) entendem que a ampliação da participação social e o aprofundamento da democracia por meio da internet tratam-se de uma espetacularização da ideia de participação. O cidadão atrás da tela encontra-se em uma posição passiva, sem saber o bastante para intervir no processo e, muitas vezes, sem vontade de fazê-lo. Ao assumir na sociedade moderna um papel análogo ao do consumidor, transforma a cidadania na busca pela maximização de interesses próprios e privados, diminuindo a participação política e a força da organização coletiva, bastando que seu interesse imediato seja atendido para que não exista insatisfação.

Tendo em conta este cenário, o presente artigo objetiva analisar os portais de transparência dos estados, avaliando o quanto eles entregam sua promessa de disponibilidade aberta de dados, possibilitando informações para que o cidadão exerça controle social sobre a administração pública.

Para atingir este objetivo foram analisados os portais de transparência dos estados com o maior PIB de cada região do Brasil, buscando (1) analisar pormenorizadamente os portais quanto a sua finalidade e facilidade de navegação, utilizando uma escala desenvolvida por Sales (2012); e (2) rastrear os repasses da federação para os estados do Fundo de Participação dos Estados e do Distrito Federal (FPE).

Os resultados indicam que os portais estudados carecem de aprimoramentos em suas interfaces, apresentando lacunas e dificuldades para a navegação e consulta aos dados públicos. $O$ rastreamento de repasses de um fundo público entre os níveis federativos exemplificou este problema, apresentando divergências de dados entre o portal federal e os dos estados, os quais tiveram que ser interpretados em cada caso específico. Além disso, todos sites analisados apresentaram fraco desempenho em termos de interatividade e participação, problematizando a propagada ideia de que a transparência pública é valorizada como meio de fomentar a participação social a partir do papel ativo da cidadania.
Conclui-se que os portais de transparência cumprem apenas a exigência legal de divulgação de informações, ainda que com ressalvas, corroborando com a visão de Filgueiras (2011) e Anjos e Ezequiel (2011), permitindo problematizar os próprios limites da transparência pública. De fato, a pesquisa indica que os portais de transparência seriam melhor caracterizados como meios pelos quais se dá visibilidade para a espetacularização do processo democrático, aumentando sua legitimidade perante a opinião pública. $\mathrm{Na}$ aparência, a busca pela redução da assimetria de informações o Estado e a sociedade civil se apresenta como uma fachada no espetáculo da cidadania, reforçando o argumento de que existe prestação de contas e que os dados estão acessíveis a todos. Na essência, a transparência reforça os mecanismos que afastam as pessoas, consumidores de serviços públicos, da responsabilidade política, reforçando o individualismo e reduzindo a força da mobilização coletiva pela exigência de mais justiça social.

\section{MARCOS LEGAIS DA TRANSPARÊNCIA PÚBLICA}

A administração pública tem como um de seus pilares a promoção do controle social ${ }^{1}$, ou seja, a prestação de contas sobre o resultado das decisões públicas. Neste sentido, é importante reconhecer que "o público tem interesse tanto na escolha das metas quanto na consecução delas" e que qualquer mecanismo com este fim "deve permitir que o público participe do debate sobre a escolha das metas, e no acompanhamento e avaliação da consecução das mesmas" (Behn, 1998, p. 37).

No Brasil, a exigência pela transparência é um processo ainda em andamento, iniciado a partir da Constituição Federal de 1988. De acordo com Silva, Jaccoud e Beghin (2005), as transformações da administração pública, especialmente a partir da assembleia constituinte, buscaram ampliar a possibilidade de envolvimento dos diversos atores sociais nas decisões políticas e na construção de políticas públicas. Ademais, a mesma também garante que a sociedade participe da gestão por meio de espaços consultivos e avaliativos, como conselhos e comissões.

Ainda, segundo os autores Silva, Jaccoud \& Beghin (2005), três princípios sintetizam o sentido que adquire a participação social a partir de então:

a) a participação social promove transparência na deliberação e visibilidade das ações, democratizando o sistema decisório; b) a participação social permite maior expressão e visibilidade das demandas sociais, provocando um avanço na promoção da igualdade e da equidade nas políticas públicas; e c) a sociedade, por meio de inúmeros movimentos e formas de associativismo, permeia as ações estatais na defesa e alargamento de direitos, demanda ações e é capaz de executá-las no interesse público. (Silva, Jaccoud \& Beghin, 2005, p. 375)

Este processo se acelera no Brasil durante a década de 1990 impulsionado por uma nova onda de reforma do Estado, marcada pela inspiração nos pressupostos da Nova Administração Pública (NAP) e pela adoção de um modelo gerencial de governo. Baseado na teoria das escolhas públicas, de essência individualista, este modelo traz como premissa a ideia de que os agentes públicos buscam também maximizar para si mesmos os benefícios da função-utilidade dos recursos públicos investidos, gerando distorções. Duas formas possíveis para lidar com isso são a 
redução do tamanho do Estado e a transparência reforçando o controle social (Andrews, 2010).

Outra característica importante dessa perspectiva de administração pública é a separação entre formulação e implementação de políticas públicas² ${ }^{2}$ amplamente dominada pelas privatizações em suas diferentes formas jurídicas e pela normatização contratual. Esta lógica implica na necessidade de modificar os controles de a priori, como era o caso da administração pública de essência burocrática ${ }^{3}$, para controles a posteriori, como no modelo gerencial, valorizando as metas de desempenho (Andrews, 2010).

Reforçando esta tendência, no ano 2000 foi promulgada a Lei Complementar $\mathrm{n}$ ํ101, objetivando o estabelecimento de normas de finanças públicas e responsabilidade na gestão fiscal, mais um passo na direção da normatização da transparência, exigindo divulgação, por canais eletrônicos de público acesso, dos planos, orçamentos, leis de diretrizes orçamentárias, prestações de conta, dentre outros. Em acréscimo, ainda obriga a União, Estados e Municípios a assegurarem a transparência por meio do incentivo à participação popular em todo o planejamento do orçamento e a adotarem um sistema integrado de administração financeira (Brasil, 2000).

Em 2009 foi sancionada a Lei nำ131/2009, também conhecida como Lei da Transparência, trazendo como inovação a obrigatoriedade de disponibilização de informações em tempo real sobre a execução orçamentária. Este processo culmina com a Lei de acesso à informação de 2011, garantindo que toda informação referente às atividades do Estado é pública, salve exceções previstas na legislação. Conforme a cartilha de orientação ao cidadão, "são seus objetivos, portanto, fomentar o desenvolvimento de uma cultura de transparência e o controle social na administração pública. Para isso, a divulgação de informações de interesse público ganha procedimentos, a fim de facilitar e agilizar o acesso por qualquer pessoa, inclusive com o uso da tecnologia da informação" (Brasil, 2011, p. 5). Nesse contexto, os portais governamentais ganham atenção e respaldo.

Este breve panorama indica existir uma gradual transformação dos marcos legais da transparência no sentido de ampliar a divulgação de dados para a sociedade civil. Justifica-se esta mudança por meio de um suposto empoderamento do cidadão, mais aparelhado para controlar a atividade pública, uma falácia que ignora as assimetrias de poder e informação entre o Estado e o indivíduo. Em meio a esse cenário, os Portais de Transparência seriam, justamente, as ferramentas mais utilizadas para efetivar o controle social, algo que só ocorre como espetáculo, como será demonstrado no decorrer do artigo.

\section{ADMINISTRAÇÃO PÚBlICA, TICs E PORTAIS DE TRANSPARÊNCIA}

No contexto contemporâneo da administração pública, a participação social passou a ser um princípio político-administrativo praticamente inquestionável (Filgueiras, 2011). O objetivo é fomentar o envolvimento cidadão, já que "criar uma rede que informe, elabore, implemente e avalie as decisões políticas tornouse o paradigma de inúmeros projetos de desenvolvimento" (Milani,
2008, p. 554). Com a evolução da internet, a crença na influência direta da sociedade civil nas decisões governamentais se fortalece, construindo um "poder de incidência política" e de demanda por controle governamental. Porém, alerta Fiabane (2011, p. 39), que é a qualidade da relação entre governo e sociedade que determina a prática do controle, sendo "necessário o exercício ativo da cidadania, por uma população bem informada que participa, acompanha e fiscaliza seus governos".

De fato, a evolução das tecnologias da informação e comunicação (TICs) teve grande impacto na administração pública. A popularização da internet modificou os processos de gestão do aparelho de Estado, especialmente no que tange aos fluxos comunicacionais, parte de um fenômeno chamado de Governo Eletrônico (Klering \& Porsse, 2014). O avanço tecnológico possibilitou mudanças na legislação, forçando os governos a gerar, organizar e disponibilizar informações de modo direto e imediato, daí a eclosão de portais de governo, aplicativos para dispositivos móveis e sistemas online para oferta de serviços públicos e os portais de transparência; cenário que trouxe novos desafios para a administração pública (Silva, 2005).

Mais do que a gestão direta dos recursos tecnológicos, os governos precisam utilizar as TICs de maneira a atender as demandas da sociedade, cumprindo seus objetivos finalísticos. $\mathrm{O}$ estabelecimento de uma governança digital demanda novas capacidades da administração pública, como o engajamento de diferentes atores no desenvolvimento e implementação de uma estratégia nacional de governo eletrônico, a necessidade do desenvolvimento de uma estrutura política e legal sobre o tema, além da divisão de trabalho e a coordenação das atividades entre os vários órgãos governamentais (Cepik, Canabarro \& Possamai, 2010).

Com a constituição do marco legal da transparência pública, a divulgação de informações em portais governamentais tornou-se um desafio para os setores de Tecnologia da Informação dos governos.

Uma das definições de portal afirma que são "sites na Internet que abrigam serviços especializados ou não, facilitando a condução do usuário por seus temas de interesse" (Leite et al., 2000, p. 279). Eles congregam uma série de conteúdos que podem estar associados por um assunto, como meio ambiente, tecnologia, saúde, etc., ou reunir diferentes temas, mas de modo organizado, para que o usuário localize aquilo que busca. É a interface do site que faz a intermediação entre a linguagem do computador e o visitante. Para os portais públicos, sua função é "traduzir, de maneira mais ágil e confortável, o conteúdo disponibilizado pelos representantes públicos e pelos usuários, uma vez que é a plataforma de convergência e acesso às informações, serviços e centros de atividades políticas e econômicas de determinado território" (Lemos et al. 2004, p. 120).

Atualmente, os sites públicos voltados para divulgação de informações são conhecidos por Portais da Transparência, existentes não apenas no governo federal, mas em todos os estados da Federação, no Distrito Federal e nos municípios, congregando diferentes funções. 
São sites nos quais a Administração divulga e disponibiliza todos os dados referentes às contas públicas, bem como aos contratos firmados, aos processos licitatórios, às obras em andamento, ao repasse aos Municípios, aos gastos com pessoal, proporcionando ao cidadão a possibilidade de acompanhar as políticas públicas que estão sendo desenvolvidas em âmbito local ou regional. (Sales, 2012, p. 38)

Os Portais da Transparência, como tema emergente no campo da Administração Pública ${ }^{4}$, foi objeto de diversas pesquisas ao longo dos últimos anos. Em nível estadual e comparativo, como é o caso desta pesquisa, destacam-se os trabalhos de Pinho (2008) e Sales (2012). O primeiro analisa portais de nove estados e o Distrito Federal, concluindo existir importantes lacunas no que tange a interação e comunicação com os usuários, o que caracterizaria os sites como ferramentas com baixo potencial para exercício da participação social. Já a pesquisa de Sales (2012), inclui todos os estados brasileiros e chega a resultados muito parecidos com Pinho (2008), corroborando a necessidade de avanços na funcionalidade dos portais.

Ainda que ambas análises cheguem a conclusões interessantes, seus resultados compartilham o mesmo nível amplo de análise, apresentando dados gerais, agregados por estado, para os sites avaliados. Neste sentido, o presente trabalho propõe avançar em uma análise pormenorizada de alguns estados representativos, o que permite tecer algumas reflexões sobre as limitações da transparência pública, efetivada mais como uma ilusão do que como um fato social.

\section{A TRANSPARÊNCIA COMO ESPETACULARIZAÇÃO}

Para além dos aspectos tecnológicos e informacionais, a transparência é questionada em sua existência material. Anjos e Ezequiel (2011) constroem o argumento de que a cidadania virtual se exerce como se fosse um espetáculo, uma imagem invertida, igualando a figura do cidadão e do consumidor em um processo aprofundado de despolitização. Assim, o que seria uma promessa de ampliação da participação social acaba por esvaziá-la ainda mais, afastando o cidadão do serviço público e atraindo-o cada vez mais para as ofertas privadas, desmobilizando a exigência coletiva de melhores condições de atendimento.

A base teórica deste argumento vem de Debord $^{5}$ (2007), para quem a sociedade moderna tornou-se a sociedade do espetáculo, na qual as imagens tornam-se o real, afirmando a aparência dos fenômenos como se fossem eles próprios, em sua essência, base da alienação social. Nessa sociedade, o fetichismo da mercadoria encontra seu ápice, moldando a realidade a sua feição e alçando o mercado a um status onipresente na vida cotidiana. São as relações de consumo que estabelecem os fundamentos dos atos humanos, reforçando a ideia de um ser humano atomizado em busca de interesses próprios. "O consumidor real torna-se consumidor de ilusões. A mercadoria é a ilusão efetivamente real, e o espetáculo é sua manifestação geral" (Debord, 2007, p. 33).

Anjos e Ezequiel (2011, p. 65), ao perceberem que a participação social eletrônica é um espetáculo, entendem que a figura do consumidor de serviços públicos, aquele que busca primordialmente o melhor para si mesmo, se reforça por meios digitais. Eles afirmam que "é nesse ambiente virtual que o espetáculo encontra suas condições ideais", já que tudo permite parecer, recriando a realidade a partir da perspectiva do consumidor-usuário, esvaziando o sentido político da participação social. Com a transparência ocorre um fenômeno análogo.

\section{ASPECTOS METODOLÓGICOS}

Este estudo utiliza duas abordagens procedimentais para o estudo dos portais de transparência. Em uma delas busca uma experiência de navegação do usuário pelas prestações de contas relativas às receitas estaduais. Para isso, utiliza como ponto de partida os valores do repasse Federal aos estados do Fundo de Participação dos Estados ${ }^{6}$ e do Distrito Federal (FPE), conforme informado no Portal da Transparência do Governo Federal, gerido e mantido pela Controladoria-Geral da União. O percurso de visitação dos sites teve como objetivo localizar o FPE na área de receita dos espaços virtuais de transparência dos estados e verificar se o valor do recurso repassado pela esfera federal coincidia com o valor declarado como recebido pelas unidades da federação.

A segunda abordagem fundamenta-se na adaptação de uma escala avaliativa desenvolvida por Sales (2012) com o objetivo de verificar se os portais de transparência dos estados se apresentam como instrumentos efetivos para o exercício do controle da atividade pública, reduzindo, assim, o distanciamento entre governo e cidadãos. Sales (2012) desenvolveu seu instrumento com base nas pesquisas anteriores de Lemos et al. (2004) e Gomes (2005). De Lemos et al. (2004), Sales (2012) apropriou a avaliação da dimensão técnica dos portais, representada no instrumento pela categoria "acessibilidade e navegabilidade". Já do trabalho de Gomes (2005), Sales (2012) incorporou três categorias ligadas à cultura política, controle e avaliação da potencialidade interativa dos portais: "prestação de informações básicas ao cidadão", "controle social sobre a administração" e "interatividade e participação". Cada uma dessas dimensões é chamada por Sales (2012) de grau, pois representam níveis no processo de transparência, do mais básico ao mais avançado.

A categoria "acessibilidade e navegabilidade" refere-se ao primeiro contato do usuário com o portal. O propósito é investigar se ele é encontrado entre as primeiras ocorrências nos resultados de sites populares de busca (Google e Yahoo) e se possui visibilidade na página inicial dos portais dos seus respectivos estados. Questiona ainda se o site provê elementos de auxílio à navegação dentro do portal, como mapa e campo próprio de busca. Este é "essencial para a visualização do conteúdo das áreas principais e suas subseções, principalmente em situações em que o usuário não obtém respostas satisfatórias no motor de busca" (Lemos et al., 2004, p. 128).

Já o tema da "prestação de informações básicas ao cidadão", em complemento ao primeiro, averígua se o ambiente digital disponibiliza dados e recursos sobre a própria razão de existir do espaço virtual e se eles estão devidamente atualizados. Questionase a disponibilidade de itens que descrevam o que é e como funciona o portal, um campo com perguntas mais frequentes, oferta de telefones de contato e se o site mostrava informações incluindo 
o mês de agosto de 2015. Recursos que expressam o "cuidado em manter um canal com o usuário visando manter, pelo menos em tese, uma funcionalidade de acordo com o interesse de quem navega" (Ibid., p. 129).

O "controle social sobre a administração" é a categoria que visa a identificar se os portais investigados cumprem, pelo menos em parte, com o que é exigido pela Constituição e pela Lei de Responsabilidade Fiscal, com a disponibilidade de dados sobre as receitas e despesas em tempo real, contratos e convênios, processos licitatórios, repasse de verbas aos órgãos que integram a administração e também aos municípios, informações e acompanhamento de obras, além das despesas com servidores e pessoal.

\begin{tabular}{|l|c|l|}
\multicolumn{2}{|l}{ Quadro 1 - Categorias e Itens do Questionário } \\
\hline Categoria & Pontuação & Itens \\
\hline $\begin{array}{l}\text { Acessibilidade } \\
\text { navegação }\end{array}$ & 4 & Resultados de mecanismos de busca; link para o portal na página do governo; mapa do site; e motor de busca próprio. \\
\hline $\begin{array}{l}\text { Prestação de } \\
\text { informações ao } \\
\text { cidadão }\end{array}$ & 4 & Informações sobre o funcionamento do portal; telefone para contato; item perguntas frequentes; e informações atualizadas. \\
\hline $\begin{array}{l}\text { Controle social } \\
\text { sobre a } \\
\text { administração }\end{array}$ & 16 & $\begin{array}{l}\text { Contratos na íntegra; convênios na íntegra; transferências do estado para os municípios; valor total anual gasto pelo estado; } \\
\text { despesas por natureza; acompanhamento online de obras; valores pagos aos servidores; valores pagos em cargos de comissão; } \\
\text { indicadores fiscais; processos de licitação finalizados e em andamento; recebimento por credores do estado; valor recebido por } \\
\text { escola; valor recebido por hospital; valor recebido por órgão; e obras realizadas pelo estado por município. }\end{array}$ \\
\hline $\begin{array}{l}\text { Interatividade e } \\
\text { participação }\end{array}$ & 8 & $\begin{array}{l}\text { Fóruns para debate; mapas interativos; ferramenta de contato com o cidadão; informações do portal em rede social; possibilidade de } \\
\text { receber informações por e-mail; disponibilidade de e-mail para contato; glossário; e espaço para denúncias e reclamações. }\end{array}$ \\
\hline
\end{tabular}

As respostas para as 32 perguntas são binárias, podendo aquele atributo estar presente ou não no portal. Cada categoria foi analisada a partir do percentual de itens atendidos, estabelecendose o mínimo de $50 \%$ para que se considere como um portal funcional em um determinado nível, seguindo a metodologia de Sales (2012).

Como amostra, foram escolhidos os portais dos estados da Bahia, Pará, Rio Grande do Sul, São Paulo e o Distrito Federal. A lógica está fundada na seleção de um representante de cada região do país. Cada um desses selecionados é o primeiro PIB dentro da sua região. Esse recorte conforma peso na decisão, já que são unidades da federação que movimentam consideráveis valores financeiros, inclusive dos repasses federais, o que, em princípio, demandariam maior atenção para constituição de ambientes de
Trata-se, então, do "acesso à res publica, ao Estado naquilo que nele deve estar sob o controle cognitivo direto do público: atos, procedimentos, registros, circunstâncias, processos legislativos e administrativos", tendo como foco aqui, os governos estaduais (Gomes, 2005, p. 14).

Por fim, o último estágio do questionário, denominado "interação e participação", foca-se nas ferramentas de relacionamento entre o Estado e o cidadão, perguntando se o portal proporciona fóruns de debates, e-mails de contato, possibilidades de recebimento de informações por meio de cadastro, interação por redes sociais e espaço para denúncias e dúvidas.

O Quadro 1 sintetiza o modelo utilizado na coleta de dados.

Figura 1- Página inicial do portal de transparência Bahia

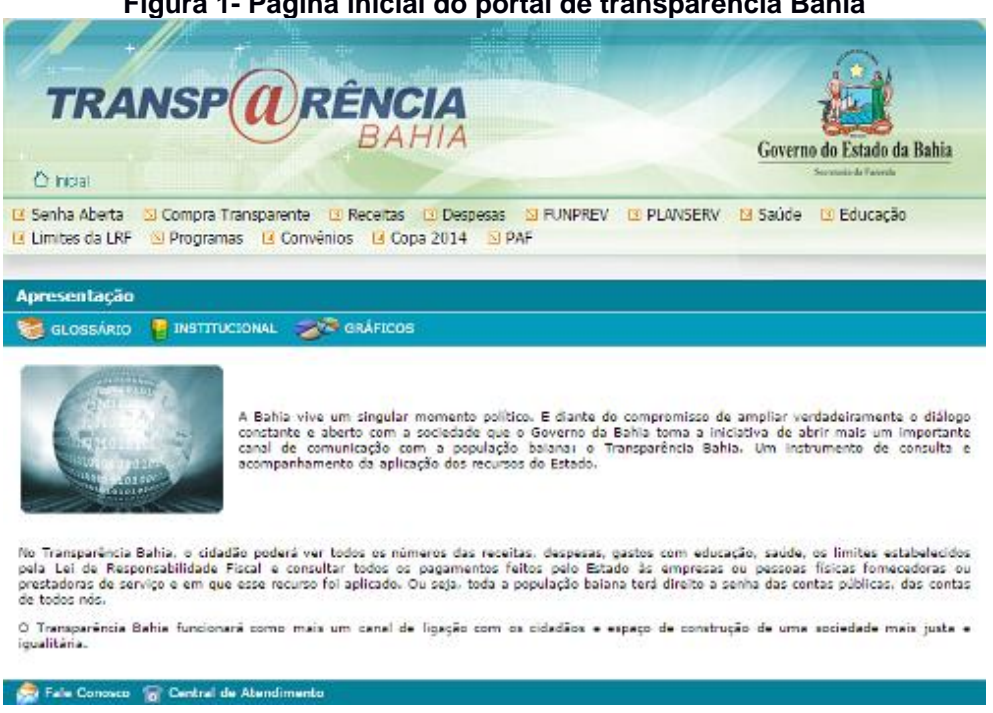

Fonte: Bahia (2015)

Disponibilizado pela Secretaria da Fazenda do Estado, o portal Transparência Bahia reúne números, em valores e percentuais, das receitas, despesas, gastos com os programas de governo, educação, saúde, fundos de custeio do Fundo de Previdência disponibilização das informações contábeis, ou seja, das despesas e receitas. Os dados são do Instituto Brasileiro de Geografia e Estatística (IBGE), cuja última referência disponível é de 2011.

Os primeiros acessos para realização deste trabalho foram efetuados em outubro de 2014, no âmbito de um trabalho acadêmico de pós-graduação. Posteriormente, os dados foram atualizados na primeira semana de setembro de 2015 para construção deste artigo.

\section{AVALIAÇÃO DE NAVEGAÇÃO NOS PORTAIS}

Segue a análise individual de cada portal e uma comparação entre eles.

\subsection{PORTAL DA TRANSPARÊNCIA DO ESTADO DA BAHIA}

$O$ site denominado Senha Aberta apresenta um design simplificado, como pode ser observado na Figura 1. 
A Tabela 1 apresenta o resultado da avaliação do portal.

Tabela 1 - Avaliação do Portal Transparência Bahia

\begin{tabular}{lc}
\hline Critérios & Pontuação \\
\hline Acessibilidade e Navegabilidade & $50,0 \%$ \\
Informações ao Cidadão & $50,0 \%$ \\
Controle Social sobre a & $37,5 \%$ \\
Administração & $37,5 \%$ \\
Interatividade e Participação & $40,6 \%$ \\
Todos os Itens &
\end{tabular}

Todos os Itens $\quad 40,6 \%$

Dentre os cinco Estados avaliados, o site da Bahia recebeu a pior nota, apesar de apresentar ligeira evolução em relação à pesquisa de Sales (2012) no item informações ao cidadão.

Com relação a acessibilidade e navegabilidade, o portal não dispõe de um mapa do site e nem de um mecanismo de busca, obtendo $50 \%$ de avaliação. Tais funcionalidades são relevantes porque facilitam a busca de conteúdos específicos.

A mesma pontuação se repete na segunda categoria. Dessa vez, o problema está em não exibir um item de "perguntas frequentes", algo que pode encurtar o tempo de obtenção de alguma informação sobre a utilização da plataforma. No entanto, a questão mais problemática é a falta de atualização do portal, já que nas duas coletas de dados realizadas as principais informações apresentam uma defasagem de 4 meses, o que impede 0 acompanhamento mais próximo das contas governamentais.

Após manter percentuais de $50 \%$ nas duas primeiras categorias, o site da Bahia entrega apenas $37,5 \%$ dos quesitos nas próximas duas categorias. Peca por não informar os contratos firmados pelo estado, nem detalha os convênios celebrados, tendo dados com atualização até 2012, metade do período da gestão de quatro anos encerrada em 2014. Apesar de informar os gastos totais com pessoal e outras naturezas de despesa como saúde, educação, meio ambiente e outros, não faz menção aos valores pagos aos servidores estaduais, nem disponibiliza a relação de servidores e as tabelas de remuneração.

O Transparência Bahia também tem média baixa com relação à possibilidade de interação do cidadão com o governo. Os únicos mecanismos existentes são um formulário de envio de mensagens e uma central telefônica para tirar dúvidas sobre o portal, não apresentando um e-mail específico de contato, nem fóruns de discussão, nem opção de cadastramento para recebimento de informações, mapas interativos ou infográficos para obtenção dos dados de investimentos nos municípios de maneira mais intuitiva e interativa.

Ao avaliar a experiência de um usuário em busca dos valores do FPE repassados pelo Governo Federal para o estado na página do Transparência da Bahia, não foram encontradas dificuldades na localização dos valores. A navegação, após a página inicial, limitouse a selecionar o item "Receita" no menu principal e, após isso, clicar em "Transferências Correntes", acima do primeiro quadro apresentado. Neste ponto, o portal já apresenta, de modo simplificado, oito transferências correntes, dentre elas o FPE. Os números são exibidos de forma aproximada, já que são valores correntes em mil Reais. No período da navegação, em setembro de 2015, o site só apresentava dados até junho. Por isso, para fins de parametrização do dado, utilizamos o exercício de 2014. Na comparação entre os valores informados pelo Transparência Bahia e o Portal da Transparência do Governo Federal, havia diferença entre os $R \$ 5.457 .891$ do primeiro e os $R \$ 6.822 .364$ do segundo (em mil reais).

Esta discrepância se explica pelo fato de que o portal do Governo Federal informa o valor já descontado dos $20 \%$ do FPE incorporados a outro fundo, o Fundeb (Fundo de Manutenção e Desenvolvimento da Educação Básica e de Valorização dos Profissionais da Educação), enquanto o Transparência Bahia declara o valor total do FPE sem o abatimento. A necessidade de interpretar o dado a partir do conhecimento da legislação e do funcionamento dos repasses é uma demonstração da assimetria informacional e da dificuldade em exercer uma cidadania ativa por meio da transparência, motivos para o esvaziamento do controle social, apontados por Filgueiras (2011).

Conclui-se que a página web do Governo do Estado da Bahia não se configura como uma ferramenta efetiva de transparência, nem mesmo nos moldes funcionais avaliados pelo questionário. Isso é fortalecido pelo percentual geral obtido pelo site de apenas $40,63 \%$, considerando o total de questões avaliadas. Foi o único dos cinco ambientes digitais com percentual mínimo ou insuficiente em todas as categorias analisadas.

\subsection{PORTAL DA TRANSPARÊNCIA DO DISTRITO FEDERAL}

O Portal da Transparência do Distrito Federal possui um visual moderno, com fácil localização dos itens principais. A página inicial disponibiliza em formato de mosaico conteúdos como despesas e receitas públicas, convênio, compras, servidores, dentre outros, como pode ser observado na Figura 2. Além de destacar a busca dos gastos por diferentes caminhos.

\section{Figura 2 - Página inicial do portal de transparência do Distrito Federal}

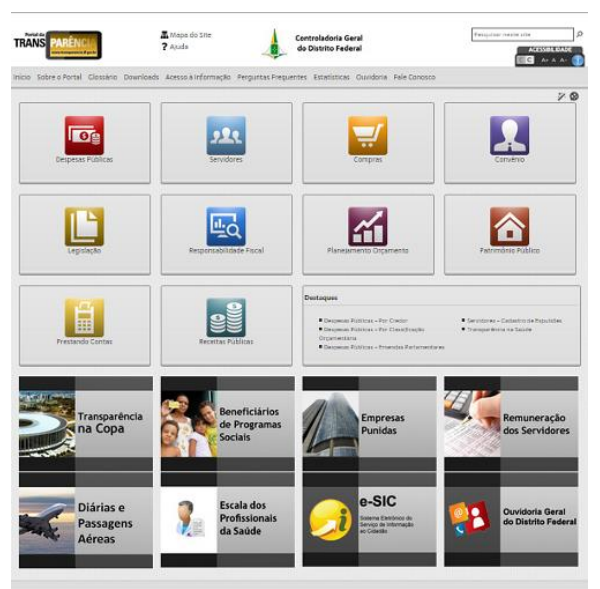

Fonte: Distrito Federal (2015)

A acessibilidade e navegabilidade são o ponto forte do site, atingindo o percentual de $100 \%$ nos itens avaliados, como pode ser observado na Tabela 2. O ambiente virtual tem motor de busca próprio, ainda que por vezes a pesquisa tenha retornado falhas nos resultados, e apresenta o mapa do site, o que facilita a localização dos elementos que compõem a página. Dos portais, é o que possui maior destaque na página do governo ao qual faz parte, tendo um banner na área nobre direcionando para a página da transparência.

Tabela 2 - Avaliação do Portal da Transparência do Distrito Federal 


\begin{tabular}{lc}
\hline Critérios & Pontuação \\
\hline Acessibilidade e Navegabilidade & $100,0 \%$ \\
Informações ao Cidadão & $75,0 \%$ \\
Controle Social sobre a Administração & $50,0 \%$ \\
Interatividade e Participação & $37,5 \%$ \\
Todos os Itens & $56,25 \%$ \\
\hline
\end{tabular}

A categoria de informações básicas ao cidadão alcança o percentual de $75 \%$, deixando apenas de disponibilizar um telefone de atendimento aos usuários. Por outro lado, garante que o visitante entenda o que é o site e como funciona, incluindo uma seção de "perguntas frequentes", além de se manter atualizado, já exibindo resultados relativos inclusive ao dia no qual se está navegando.

O nível do desempenho do Portal da Transparência do DF cai nas categorias seguintes. No controle social sob a administração, ganha pontos por disponibilizar informações sobre convênios, pagamentos a servidores, licitações e a busca de gastos por credor, mas chega apenas ao percentual limítrofe de $50 \%$. Isso ocorre por conta da falta de transparência relacionada aos contratos firmados pelo Distrito Federal e ao acesso a gastos pela natureza da despesa, como saúde, educação, segurança, meio ambiente e outros.

O Distrito Federal chega ao pior percentual na quarta categoria: $37,5 \%$. É considerado baixo o estímulo à interatividade e participação, já que o portal, apesar de possuir um Fale Conosco, não dispõe de fóruns de discussão, possibilidade de cadastramento por e-mail para receber informações e nenhum tipo de mapa interativo com dados e gastos por região administrativa.

Em comparação com Sales (2012), houve apenas uma ligeira melhoria no item controle social sobre a administração pública, com a disponibilização da origem de algumas despesas.

Com relação ao FPE, o site do Distrito Federal não indicava um valor único em sua receita para o recebimento de recurso do Fundo de Participação dos Estados e Distrito Federal. Ao navegar em busca do detalhamento, o portal apresentava vários links para mesma opção como as transferências correntes, intergovernamentais e da União. Como a busca não estava funcionando corretamente, foi difícil localizar o FPE. Uma vez encontrado, o valor expresso era de $\mathrm{R} \$ 363.444$ (mil reais) até 01 de setembro de 2015, 29\% acima dos $\mathrm{R} \$ 259.491$ (mil reais) indicados pelo portal da transparência do governo federal.

Trata-se de um problema, portanto, que o portal não ofereça condições para que o cidadão verifique esse elemento constituinte das receitas do Distrito Federal de maneira clara e compreensiva. Essa constatação se coaduna com o percentual insatisfatório (50\%) obtido pelo site na categoria controle social sobre a administração.

Mais uma vez a dificuldade de navegação e acesso à informação corrobora com a tese de Filgueiras (2011), sobre as fragilidades do processo de transparência e de Anjos e Ezequiel (2011), sobre a espetacularização. A divulgação de dados parece simplesmente obedecer a um processo mecânico para cumprir uma obrigação legal, não indo além do mínimo. Ao tentar se aprofundar no processo de análise de dados, o cidadão necessita de conhecimentos básicos sobre legislação e contabilidade pública, conteúdo específico fora do domínio de grande parte da população. Se a transparência fosse um real interesse poderia ser mais simplificada, feita para ser compreendida sem a necessidade de mediações (Anjos \& Ezequiel, 2011).

Na média geral, a ferramenta de transparência do governo do DF atinge um percentual de $56,25 \%$, considerando o total das questões, sendo eficaz nas duas primeiras categorias, navegabilidade e informações básicas, mas fraco nas categorias que analisam as possibilidades de controle social e interatividade com a administração pública. São justamente as últimas que geram espaços para que pessoas e coletividades possam se engajar na vida política por meio da internet, defendendo interesses e participando ativamente do controle social.

\subsection{PORTAL DA TRANSPARÊNCIA DO ESTADO DO PARÁ}

O portal da transparência do Estado do Pará, maior participação no PIB nacional da Região Norte, apresenta-se em três colunas. À esquerda, um menu dividido em duas categorias: informações e relatórios. Na coluna do meio, itens mais acessados, como receitas, despesas, servidores, fale conosco e glossário. À direita, uma sequência de banners de outras páginas de transparências relativas a diferentes órgãos estaduais.

\section{Figura 3 - Página inicial do portal de transparência do Estado do Pará}

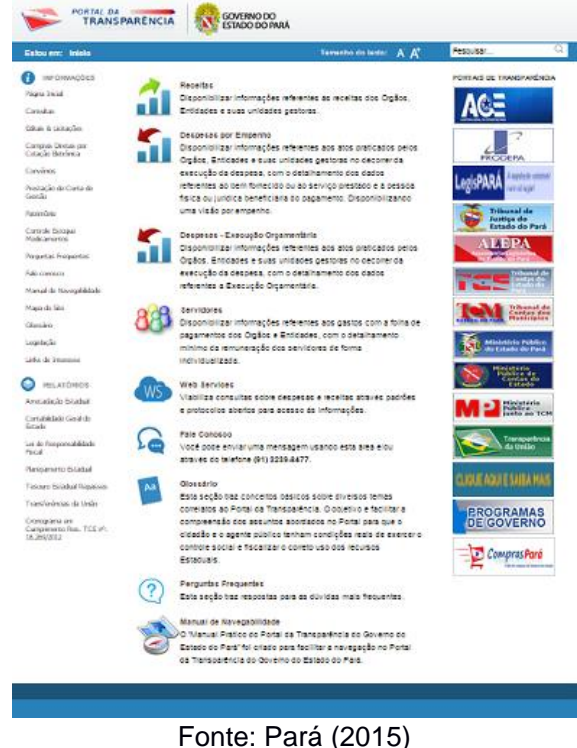

O portal tem um resultado positivo na categoria de acessibilidade e navegabilidade, alcançando $100 \%$ de percentual, por disponibilizar mapa do site e motor de busca próprios, além de ter um link com visibilidade para o site do executivo. Também aparece dentre os primeiros resultados em sites populares de busca, como Google e Yahoo.

Tabela 3 - Avaliação do Portal da Transparência do Pará

\begin{tabular}{lc}
\hline Critérios & Pontuação \\
\hline Acessibilidade e Navegabilidade & $100,0 \%$ \\
Informações ao Cidadão & $75,00 \%$ \\
Controle Social sobre a Administração & $43,75 \%$ \\
Interatividade e Participação & $50,00 \%$ \\
Todos os Itens & $56,25 \%$ \\
\hline
\end{tabular}


Na categoria informações básicas ao cidadão, o site atinge um resultado de $75 \%$. Apresenta o mesmo ponto fraco verificado no Senha Aberta da Bahia, que é não possuir dados atualizados para o tempo presente. Ademais, algumas buscas, como "Despesas Execução Orçamentária" do órgão Secretaria de Saúde, não retornam resultados para consulta de 2014 e 2015.

A pior classificação do portal é na categoria de controle social sobre a administração, ficando com um percentual de $43,75 \%$ de atendimento aos itens exigidos. O site não provê informações sobre contratos, obras e valores pagos a cargos comissionados. Principalmente, não exibe de forma fácil e clara o valor total gasto pelo estado no período de um ano, nem as despesas pela sua natureza, como educação, saúde, segurança e outros. Apesar de ter uma área voltada para convênios, não consegue mostrar os repasses financeiros efetivamente realizados e o detalhamento acaba ocorrendo por meio de imagens de páginas publicadas no diário oficial do estado.

Ao analisar os itens que atestam as ações de interação com o cidadão, o site volta a não atingir o esperado, apresentando apenas $50 \%$ dos itens da categoria. Assim como os portais da Bahia e do Distrito Federal, não possibilita fóruns de discussão, cadastramento por e-mail para receber novas informações e nem interatividade por meio de mapas com dados de municípios ou outros.

Ademais, a busca pela entrada de receita com a rubrica do Fundo de Participação dos Estados e do Distrito Federal não atingiu o objetivo. O site não apresenta mais do que um nível de detalhamento de despesas e receitas. Ao clicar em "receita", o usuário é levado a um formulário para selecionar apenas o ano e uma dentre duas opções de pesquisa: por receita ou por órgão. Selecionando a primeira, o resultado da solicitação é um quadro no formato de planilha, com três colunas: Categoria Receita, Origem e Receita Realizada. Não é possível, por exemplo, clicar em um dos campos de "Origem" para obter detalhamentos de transferências correntes, chegando a dados específicos, como o FPE.

Portanto, o site de transparência paraense não se configura como uma ferramenta efetiva de participação e transparência, não alcançando os escores mínimos para avaliações de controle social da administração ou interação com a sociedade civil e nem conseguindo fornecer uma experiência de localização de uma receita que é permanente e frequente como o FPE. A impossibilidade de detalhar dados de despesa e receita, além da inoperância de certas buscas e a desatualização de alguns dados, comprometem parte relevante de sua função, que é permitir ao cidadão acompanhar a arrecadação, os investimentos, e pagamentos de maneira mais precisa. Tais constatações são reforçadas pelo fato do site só responder positivamente a 18 das 32 questões do questionário, chegando a $56,25 \%$ na escala de avaliação. Ainda assim, comparando com os resultados de Sales (2012), houve uma melhoria, considerando que a avaliação do portal estava em $47,7 \%$.

\subsection{PORTAL DA TRANSPARÊNCIA DO ESTADO DO RIO GRANDE DO SUL}

O Rio Grande do Sul é o estado da região mais meridional do país com maior participação no PIB nacional. O seu portal de transparência apresenta uma interface simplificada, com duas áreas mais destacadas. À esquerda, encontra-se o menu principal com links para conteúdos como O que é o Portal, Como Consultar, Origem dos Dados, Perguntas Frequentes, Participação e Controle Social e outros. À direita, estão localizados os destaques e os acessos diretos aos gastos e receitas, além de itens como convênios e contratos.

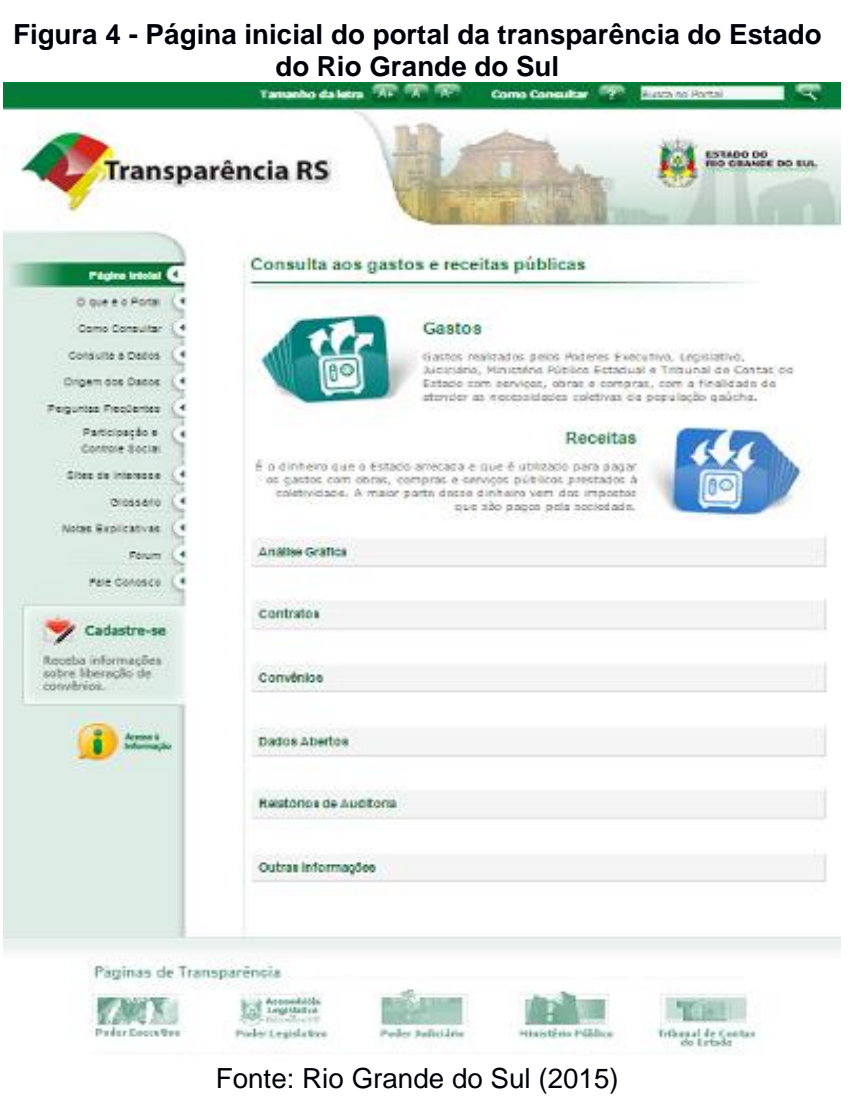

A acessibilidade e navegabilidade não são potencialidades do site gaúcho, que só atingiu o percentual de $50 \%$, piorando em relação a coleta de dados de Sales (2012) por desabilitar os serviços de mapa de navegação e link ou banner para o portal da transparência diretamente na página inicial do estado.

\begin{tabular}{l|c}
\multicolumn{2}{c}{$\begin{array}{c}\text { Tabela 4 - Avaliação do Portal da Transparência do Rio } \\
\text { Grande do Sul }\end{array}$} \\
\hline Critérios & Pontuação \\
\hline Acessibilidade e Navegabilidade & $50,00 \%$ \\
Informações ao Cidadão & $100,00 \%$ \\
Controle Social sobre a Administração & $75,00 \%$ \\
Interatividade e Participação & $62,50 \%$ \\
Todos os Itens & $71,88 \%$ \\
\hline
\end{tabular}

O portal, no entanto, supera o percentual de $50 \%$ em todas as demais categorias, começando pelos 100\% nas informações básicas ao cidadão. A disponibilização de perguntas frequentes, telefone de contato com o órgão responsável e conteúdo sobre o que é o portal e como funciona está contemplada na ferramenta digital. Em acréscimo, ainda mantém seus dados atualizados, de modo que já contempla o mês de agosto de 2015, período imediatamente anterior a coleta de dados.

Dentre os cinco Estados avaliados, o Rio Grande do Sul foi o 
que atingiu maior percentual na categoria de controle social sobre a administração, chegando a $75 \%$. Ele atende aos requisitos de verificação de contratos e convênios e dos valores transferidos aos municípios e órgãos da administração, incluindo os gastos totais por natureza (pastas como segurança, transporte e meio ambiente) e relacionados aos servidores. Além disso, permite 0 acompanhamento de licitações em tempo real. Entre todos analisados, foi o único site que disponibilizou os valores pagos aos cargos comissionados, ainda que para isso encaminhe o usuário para uma página da Secretaria da Fazenda e para um documento em formato PDF, ou seja, sem ser uma página web.

O portal gaúcho ultrapassou o percentual mínimo na última categoria, de interação e participação, atingindo $62,5 \%$. Foi o único ambiente digital a proporcionar espaço para fórum, ainda que não tenha um tópico de discussão novo desde 2011 e que os últimos tópicos não tenham resposta. Ademais, somente este site entre os pesquisados possibilita 0 cadastramento de e-mail para recebimento de informações, mesmo que elas sejam restritas ao conteúdo de convênios.

Adicionalmente, neste site é possível obter visões de receitas de diferentes formas, seja pelo valor acumulado ou mensal, pelo ano do exercício ou pelo mês a ser consultado. Também é possível selecionar esses recebimentos por sua classificação econômica ou finalidade do recurso. Pelo último, foi localizada uma única referência ao FPE com uma certa dificuldade de navegação. Pela classificação econômica, foi possível chegar ao valor de $\mathrm{R} \$ 1$ 1.312.382.847,32 de acordo com o portal do Governo do RS. Já o portal da transparência federal indicava um montante menor, na ordem de $\mathrm{R} \$ 994.170 .830,00$. Não há explicação aparente para o desencontro próximo a $25 \%$ entre os dados de origens distintas, demonstrando a dificuldade do cidadão em obter informações adequadas e claras sobre a administração pública. Aqui, a assimetria de informações que coloca em xeque a transparência como uma possibilidade real e efetiva, evitando a formação da responsabilidade política, tão importante na perspectiva do controle social. Segundo Filgueira (2011), trata-se de um problema insolúvel no âmbito da administração pública.

Caso o portal de transparência do Estado do Rio Grande do Sul apresentasse um mapa do site ou um simples e essencial acesso na página inicial do governo estadual, poderia melhorar seu desempenho no critério de acessibilidade e navegabilidade. No entanto, o site supera os $50 \%$ previstos neste trabalho como ponto de corte para se classificar um portal como um espaço adequado de informações básicas ao cidadão, atingindo $71,88 \%$ na escala de avaliação, maior percentual entre os casos analisados.

\subsection{PORTAL DA TRANSPARÊNCIA DO ESTADO DE SÃO PAULO}

O portal da transparência do Estado de São Paulo, unidade da federação com maior participação no PIB nacional e representante da região sudeste na pesquisa, se organiza principalmente por meio de blocos distribuídos em linhas e colunas, postados na parte mais central da página. Acima, um menu de links com destaque menor, abaixo, banners com links para órgãos com atuação associada à transparência governamental.
Figura 5 - Página inicial do portal de transparência do Estado de São Paulo

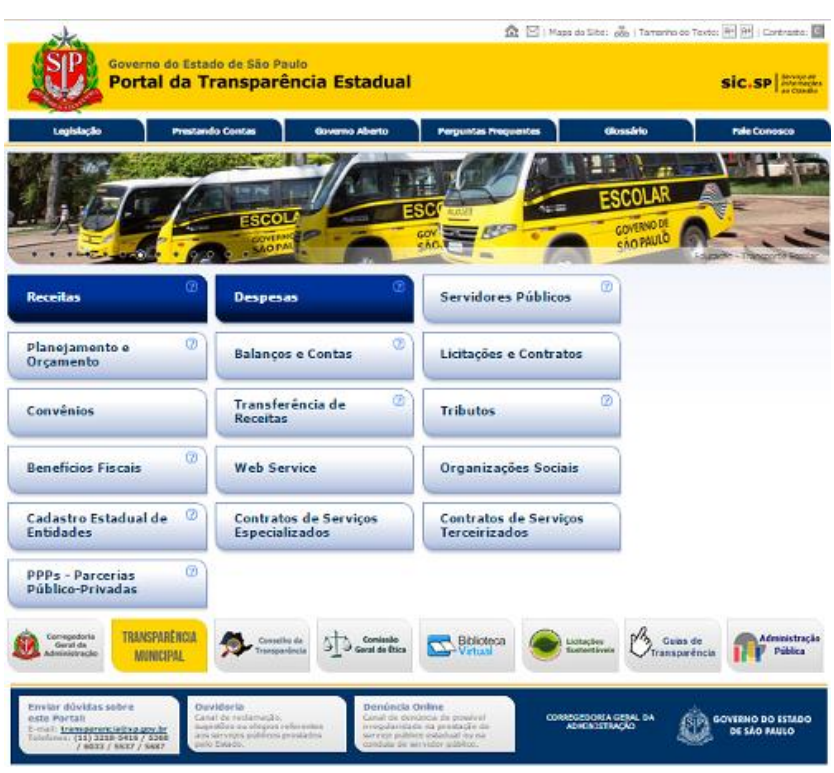

Fonte: São Paulo (2015)

São Paulo tem o único portal dos cinco casos estudados que obteve percentual cima dos $50 \%$ em todas as quatro categorias, como pode ser observado na Tabela 5.

Tabela 5 - Avaliação do Portal da Transparência de São Paulo

\begin{tabular}{ll}
\hline Critérios & Pontuação \\
\hline Acessibilidade e Navegabilidade & $75,00 \%$ \\
Informações ao Cidadão & $75,00 \%$ \\
Controle Social sobre a Administração & $68,75 \%$ \\
Interatividade e Participação & $62,50 \%$ \\
Todos os Itens & $68,75 \%$ \\
\hline
\end{tabular}

O quesito acessibilidade e navegabilidade teve $75 \%$ de atendimento aos requisitos testados. A única falta foi a não inclusão, dentre as suas funcionalidades, de um espaço próprio para consulta. Conta, porém, com mapa do site, resposta dentre os primeiros resultados nos principais sites de pesquisa Google e Yahoo, além de link na página inicial do site do governo estadual.

Também assegura $75 \%$ dentre os elementos voltados para as informações básicas ao cidadão. Mais uma vez, apenas um elemento não foi contemplado: a existência de uma área com informações sobre o portal e como ele funciona.

$\mathrm{Na}$ terceira categoria, do controle social sobre a administração, o site paulista passa novamente os $50 \%$, aferindo $68,75 \%$ dos itens avaliados. Destaca-se por conter o detalhamento sobre convênios e contratos, o acesso ao gasto total da gestão por ano e por natureza da despesa, além dos repasses aos municípios. Mesmo tendo criado um espaço com dados sobre a relação e salários de servidores e, ainda, as tabelas de remuneração, não permite o conhecimento sobre o quanto é gasto com os cargos em comissão.

O pior percentual do portal de São Paulo está na quarta categoria, ficando com $62,8 \%$ dos indicadores utilizados. Ressaltase a existência de espaços específicos para reclamações e sugestões, dúvidas e denúncias na barra inferior do site. Contudo, não há espaço próprio para interação, não existindo ambiente de fórum ou mesmo mapas interativos com informações dos municípios.

$\mathrm{Na}$ busca pelas receitas financeiras paulistas, o site oferece 
diferentes formas de pesquisa: pré-formatada, livre, temporal e atualização mensal, além de gráficos e relatórios. Selecionando a atualização mensal, optou-se pelos dados anuais ao invés dos dados mensais, clicando em Transferências Correntes, Transferências intergovernamentais e, na planilha exibida, localizou-se o item FPE: Cota-parte Fundo Participação dos Estados, com o valor de $\mathrm{R} \$ 460.726 .175,36$. Já a informação do portal de transparência do Governo Federal indica R\$ 422.189.073,91. Como o site de São Paulo demonstra os repasses federais mensais, foi possível perceber que a diferença de $\mathrm{R} \$ 38.537 .101,45$ corresponde exatamente ao valor recebido no mês de setembro, indicando que o portal do estado está mais atualizado do que o federal.

Ainda assim, apesar da atualização de dados ser um ponto alto, o portal da transparência de São Paulo não obteve $100 \%$ de atingimento dos requisitos para nenhuma das quatro categorias do questionário. O percentual geral, tendo em conta todos os itens do questionário, chegou a $68,75 \%$, o que corresponde a dizer que atendeu a 22 das 32 questões.

\section{DISCUSSÃO DE RESULTADOS}

A transparência pública é um dos elementos de um processo de reforma do Estado ainda em andamento. O modelo gerencial pressupõe o direcionamento do controle para o foco nos resultados das atividades públicas (Andrews, 2010), suportado teoricamente por uma visão que separa público e privado, unindo-os novamente por meio da teoria da agência (Filgueiras, 2011). Por esta perspectiva, aquele que é um agente público deve ser controlado por aqueles que nele confiaram, garantindo que não coloque seu interesse próprio acima das decisões pelo bem comum. O problema é a existência de uma assimetria de informações que dificulta o exercício do controle social, espaço no qual a transparência surge como necessidade e obrigação, impulsionando legislações e novas ferramentas.

Pode-se afirmar que a política da transparência se tornou uma espécie de lugar comum na política das sociedades liberais. De lugar comum, passou a uma espécie de panaceia para as delinquências do homem público e a ineficácia institucional. Diante de casos de corrupção, clama-se por maior transparência das instituições, pela abertura das contas públicas e pela moralização da política (Filgueiras, 2011, p. 75).

A ideia de responsabilidade política torna-se assim, elemento fundamental de qualquer projeto democrático no contexto do neoliberalismo. Entretanto, "é impossível pensar a responsabilidade política sem que as instituições sejam transparentes aos cidadãos e que o déficit de informação entre o homem comum e as instituições democráticas seja reduzido [...] a democracia pressupõe uma espécie de livre conhecimento por parte do cidadão comum" (Filgueiras, 2011, p. 75).

O que a pesquisa realizada neste artigo demostra é uma realidade distante do otimismo de Fiabane (2011), Klering e Porsse (2014) e Lemos et al. (2009), quando se referem ao uso das TICs na administração pública como uma espécie de reforço da democracia representativa a partir do fortalecimento da cultura política de participação. Considerando os graus de funcionalidade do instrumento de pesquisa, os portais de transparência dos estados entregam alguma confiança em termos de navegação e acessibilidade e informações ao cidadão, deixando a desejar em termos de controle social e, principalmente, interatividade e participação. Com indicadores muito próximos do mínimo aceitável e uma evolução apenas modesta com relação à pesquisa de Sales (2012), conclui-se que os portais de transparência ainda são instrumentos de baixa capacidade em termos de fomentar a responsabilidade política, sendo melhor caracterizados como formas de cumprir a legislação vigente. Soma-se a isso o exemplo dos problemas em rastrear o FPE e compreender a forma como os repasses são representados. Mesmo para pesquisadores conhecedores do assunto, em alguns casos, como no RS, não foi possível interpretar a diferença entre os dados dos portais federal e estadual.

Os resultados reforçam o entendimento da transparência como espetáculo, com base nas críticas de Anjos e Ezequiel (2011), inspirados em Debord (2007). De fato, frente a todas as limitações e dificuldades encontradas no processo de utilização dos Portais de Transparência, questiona-se o quanto tais mecanismos podem, efetivamente, contribuir para o fortalecimento da participação social. Além de terem problemas internos para funcionar como meio de divulgação de dados, também tem problemas externos e finalísticos, já que o cidadão que vive na sociedade do totalitarismo da mercadoria é, antes de tudo, um consumidor, não exigindo aquilo que não tem relação direta com seu consumo. A suposta união entre o papel de cidadão e consumidor, baseada na crença de que alguém informado poderia exigir mais de um Estado prestador de serviços, aprofunda, de fato, um hiato entre o consumidor de serviços públicos e o cidadão de responsabilidades políticas, já que conforma o indivíduo atomizado a avaliar somente aquilo que recebe em troca de seus impostos, vendo nitidamente a árvore em detrimento da floresta. Parece que há um maior controle, porém o que existe é um distanciamento cada vez maior daquele que representa e daquele que é representado, reforçando o espetáculo como medida do real e a transparência como mais uma faceta do fetiche moderno.

\section{CONSIDERAÇÕES FINAIS}

Este estudo buscou analisar a funcionalidade dos portais de transparência de governos dos cinco estados com maior participação no PIB nacional por região.

A aplicação do instrumento de pesquisa permitiu uma visão detalhada, abordando aspectos estruturais e de disponibilidade dos dados. A busca dos valores do Fundo de Participação dos Estados e do Distrito Federal (FPE) possibilitou uma experiência de navegação específica que cooperou para fazer uma breve verificação da relação entre os valores de despesa informados pelo governo federal e os da receita dos estados investigados, exemplificando as dificuldades encontradas pelo cidadão. As diferenças de valores encontradas na Bahia e em São Paulo foram explicadas por falta de atualização e forma de agregação de dados, porém, no Rio Grande do Sul e no Distrito Federal, não foi possível explicar a discrepância. Ainda pior foi o resultado da busca no site 
do Pará, não sendo possível nem mesmo localizar o repasse do fundo em questão.

$\mathrm{Na}$ análise conjunta do desempenho dos portais de transparência pesquisados, as duas primeiras categorias, "acessibilidade e navegabilidade" e "informações básicas ao cidadão", contaram com um melhor percentual de atingimento dos requisitos esperados nas ferramentas digitais. Em relação à categoria "controle social sobre a administração", o resultado foi abaixo da média, visto que apenas Rio Grande do Sul e São Paulo conseguiram avaliações superiores a $50 \%$. São os únicos que, por exemplo, disponibilizam acesso a dados mais detalhados sobre os contratos realizados por seus governos. Cabe ressaltar que quatro itens nesta categoria não foram localizados em nenhum dos portais pesquisados: acesso a informações ou ao acompanhamento online de obras, investimento em escolas e hospitais das redes públicas. Por fim, o pior resultado foi encontrado nos elementos relativos à interação e estímulo à participação dos indivíduos na vida política, com apenas os estados de São Paulo e Rio Grande do Sul atingindo percentuais acima de $50 \%$.

Portanto, em termos gerais, ainda que os resultados não possam ser generalizados para todo Brasil, os sites estudados apresentam muitos problemas e insuficiências. Esse fato demonstra que ainda falta um longo caminho a percorrer para que estes espaços digitais se tornem ambientes com "informação instrumental necessária para que a cidadania usufrua dos serviços do Estado, possa exercer cobrança e pressão sobre governos[...]" e "tenha controle cognitivo sobre o estado dos negócios públicos" (Gomes, 2005, p. 14)

Sendo assim, constata-se a falta de uma visão mais ampla do processo de acesso à informação como empoderamento da sociedade civil, refletida na construção de portais como simples resposta às leis que exigem a transparência das finanças governamentais. A própria experiência de ser um usuário em busca de uma informação específica demonstrou como em diversos momentos o conhecimento prévio acaba sendo relevante para uma busca dos diferentes tipos de despesas e transferências. Este estudo não pretendeu propor uma organização de conteúdo ou um novo design aos sites verificados, mas como visitantes de tais espaços, percebe-se que não são orientados aos usuários e a simplificar a fiscalização cidadã das contas públicas.

Sem a superação destas dificuldades os portais de transparência apenas contribuem para o reforço da espetacularização da participação social por meio eletrônico, conforme analisaram Anjos e Ezequiel (2011). Tal participação, longe de se converter em um processo de mudanças efetivas nos mecanismos que regulam a relação entre Estado e sociedade civil, apenas reforça a posição de um Estado que paira sobre os interesses sociais, conforme analisa Pinho (2008).

Por fim, pode-se dizer que o conceito de cidadania espetacularizada, criado por Anjos e Ezequiel (2011), pode ser adaptado aqui para transparência como espetáculo. A transparência como espetáculo critica a própria noção da disponibilidade de informações, permitindo compreender que aquilo que é revelado como real, ao entrar em relação com um sujeito que tenta interpretar os dados sem conhecimento para tal, adquire um caráter fetichista, aparentando ser um veículo de engajamento sem nunca mostrar a essência da administração pública. Revelam-se dados e contratos que precisam ser interpretados, forjando um espetáculo que cria a imagem de uma cidadania possível, passando para as pessoas a responsabilidade pelo controle social da atividade pública, sem que isso, no entanto, seja efetivado como prática social. A essência das relações sociais de poder que estão por trás do desenho das políticas públicas e da construção das peças orçamentárias não se revela ao usuário do Portal da Transparência que tem diante de si uma parte ofuscada da realidade, reforçando o fetichismo da democracia na Sociedade do Espetáculo, analisada por Debord (2007).

\section{REFERÊNCIAS}

Andrews, C. (2010). Da Década Perdida à Reforma Gerencial: 1980-1998. In Andrews, C.; \& Bariani, E. (2010). Administração Pública no Brasil: breve história política. São Paulo: UNIFESP.

Anjos, G., \& Ezequiel, V. (2011). Cidadania Virtual: o espetáculo do governo eletrônico. Estudos de Sociologia, 16 (30), 59-76.

Akutsu, L., \& Pinho, J. Antonio. (2003). Sociedade da informação, accountability e democracia delegativa: investigação em portais de governo no Brasil. Revista de Administração Pública, 36 (5), 723-746.

Bahia (Estado). (2015). Portal Transparência BAHIA. Secretaria da Fazenda. Recuperado

http://sistemas.sefaz.ba.gov.br/sistemas/tbweb/modulos/home/main.aspx

Behn, R. (1998). O novo paradigma da gestão pública e a busca da accountability democrática. Revista do Serviço Público, 4.

Borges, J., Nascimento, J., \& Silva, H.P.. (2005). Análise das informações disponibilizadas no portal de serviços e informações do Governo Federal. Diálogo Científico.

Brasil. (2000). Lei Complementar $n^{0} 101$, de 4 de Maio de 2000. Estabelece normas de finanças públicas voltadas para a responsabilidade na gestão fiscal e dá outras providências. Diário Oficial [da] República Federativa do Brasil, Brasília, DF.

Brasil. (2011). Lei de Acesso à Informação: cartilha de orientação ao cidadão. Centro de Documentação e Informação, edições câmara, Brasília.

Cepik, M., Canabarro, D.., \& Possamai, A. (2010). Gerencialismo Público à Governança da Era Digital. In: Cepik, M., \& Canabarro, D. R. Governança de TI: Transformando a Administração Pública no Brasil. Porto Alegre: WS Editores.

Cruz, C.F.; Ferreira, A.; Silva, L.; Macedo, M. (2012). Transparência da gestão pública municipal: um estudo a partir dos portais eletrônicos dos maiores municípios brasileiros. Revista de Administração Pública, 46 (1), 153-176.

Cunha, M.A., \& Miranda, P.R. (2013). O uso de TIC pelos governos: uma proposta de agenda de pesquisa a partir da produção acadêmica e da prática nacional. Organizações e Sociedade, 20 (6).

Debord, G. Sociedade do Espetáculo. (2007). Contraponto: São Paulo.

Distrito Federal (2015). Portal da Transparência. Controladoria Geral do Distrito Federal. Recuperado de http://www.transparencia.df.gov.br/Pages/inicio.aspx

Fiabane, D. F. (2011). Controle social: um novo frame nos movimentos sociais. Dissertação de Mestrado, Escola de Administração de Empresas da Fundação Getúlio Vargas.

Filgueiras, F. (2011). Além da Transparência: Accountability e Política de Publicidade. Lua Nova, 84, 353-364.

Gomes, W. (2005). A democracia digital e o problema da participação civil na decisão política. Revista Fronteiras, São Leopoldo, VIII (3), 214-222.

Juzzo, L. M. L. C. (2004). Critérios para avaliação da qualidade das informações sobre saúde disponíveis online. Anais do IX CBIS.

Klering, L. R., \& Porsse, M.C.S. (2014) Em Direção a uma Administração Pública Brasileira Contemporânea com Enfoque Sistêmico. Desenvolvimento em Questão, 12 (25), 41-80.

Leite, A.P., \& et al. Portais da Internet. (2000). Revista de Administração Pública, 34 (1), 279-289.

Lemos, A., \& et al. (2004). Cidade, Tecnologia e Interface. Análise de Interfaces de Portais Governamentais Brasileiros. Uma proposta metodológica. Revista Fronteiras, VI (2), 117-136.

Lemos, A., \& Lévy, P. (2000). O futuro da internet: em direção a uma ciberdemocracia planetária. São Paulo: Paulus.

Milani, C.R.S. (2008). O princípio da participação social na gestão de políticas públicas locais: uma análise de experiências latino-americanas e europeias. Revista de Administração Pública, Rio de Janeiro , 42 (3).

Pará. Portal Transparência do Governo do Estado do Pará. Secretaria da Fazenda. Recuperado de http://www.transparencia.pa.gov.br 
Pinho, J., \& Sacramento, A.R. (2009). Accountability: já podemos traduzi-la para o português? RAP, 43 (6), 1343-1368.

Pinho, J.A.G. (2008). Investigando portais de governo eletrônico de estados no Brasil: muita tecnologia, pouca democracia. Revista de Administração Pública, 42 (3), 471-493.

Rio Grande Do Sul (2015). Transparência RS. Recuperado de http://www.transparencia.rs.gov.br.

Sales, T. (2012). Acesso à Informação, Controle Social das Finanças Públicas e Democracia: Análise dos Portais da Transparência dos Estados Brasileiros

${ }^{1}$ Evitamos propositalmente a utilização do termo accountability, entendendo que por ser um conceito que enseja uma vasta pluralidade de interpretações, conforme demonstra o estudo de Pinho e Sacramento (2011), sua utilização no presente trabalho não contribuiria para o fortalecimento de seu argumento central.

${ }^{2}$ Esta separação encontra amparo teórico na teoria da agência, segundo a qual os principais seriam os formuladores de políticas públicas e os agentes seus executores, incluindo organizações da sociedade civil, órgãos públicos e empresas privadas no contexto da NAP.

${ }_{3}^{3}$ Ainda que seja importante frisar que a administração pública gerencial não modifica o essencial da burocracia enquanto aparato organizacional da forma de dominação racional-legal, conforme originalmente conceituado por Weber (1999).

${ }^{4}$ Utilizamos o termo "Administração Pública" em maiúsculas por referir-se a um campo acadêmico.
Antes e Após o Advento da Lei no 12.527/2011. Direito Público, 9 (48). São Paulo (2015). Portal da Transparência Estadual do Governo do Estado de São Paulo. Recuperado de http://www.transparencia.sp.gov.br

Silva, F.B., Jaccoud, L., \& Beghin, N. (2005). Políticas sociais no Brasil: participação social, conselhos e parcerias. In: JACCOUD, L. (Org.). Questão social e políticas sociais no Brasil contemporâneo. Brasília: Ipea, 373-407.

Silva, S.P. (2005). Graus de participação democrática no uso da Internet pelos governos das capitais brasileiras. Opinião Pública, Campinas, XI (2), 450-468. Weber, M. (1999). Economia e Sociedade. Editora da UNB: Brasília

5 Ainda que discordemos de Debord (2007) na imaterialidade de seu argumento central, escorregando no exagero estilístico de sua própria tese, mal que compartilha com outros pós-modernos, chegando a dizer que o capital em um grau superior de acumulação transforma-se em imagem, entendemos que a apropriação do conceito de espetáculo para a análise do objeto em questão é apropriada.

${ }^{6} \mathrm{~A}$ relevância desse procedimento está em averiguar o nível de integração dos dados governamentais, além de identificar a aderência das informações providas pelos portais às determinações legais da Lei de Responsabilidade Fiscal (LRF). Já que o Brasil é organizado como federação, com a União e os entes federados guardando entre si relacionamento ininterrupto, é assegurado por meio dos dispositivos constitucionais e legais o atendimento a normas nacionais, como a LRF e a realização de intercâmbios financeiros, como o FPE. 